\title{
Research Trends in Knowledge Management in Military
}

\author{
Rasa SMALIUKIENE ${ }^{1}$, Vidmantė GIEDRAITYTE ${ }^{2}$
}

\author{
${ }^{1,2}$ Department of Management, General Jonas Žemaitis Military Academy of Lithuania, Silo g. 5A, \\ LT-10322 Vilnius, Lithuania \\ E-mails: ${ }^{1}$ rasa.smaliukiene@lka.lt; ${ }^{2}$ vidmante.giedraityte@lka.lt
}

\begin{abstract}
The objective of this study is to review current research on knowledge management in military and to identify the main streams where research is performed. Knowledge in the military is perceived as a tool and means for effectiveness and has been analyzed from diverse standpoints. Accordingly, the studies in this field take different paradigms and represent the perspective of management, social networking, organizational psychology, information technology and other fields towards the phenomena of knowledge in the military and its management practices. Although previous studies on knowledge management in military have presented some literature overviews, this study is the first to provide a systematic analysis using content mapping.

Systematic literature review using in-depth text mining and bibliometric networks are used as methods for this study. The data consist of theoretical, analytical and research papers retrieved from Web of Science Clarivate Analytics (VoS) $(\mathrm{N}=406)$ and Scopus databases $(\mathrm{N}=317)$. According to findings, knowledge management research in the military is performed in three streams. The larges stream represents management science paradigm. The second largest stream represents interdisciplinary perspective and the smallest stream is predominated by technical solutions in the military knowledge management. The results of in-depth text mining identify the recent trends in knowledge management research in the military. They are associated with knowledge integration and strategy.
\end{abstract}

KEY WORDS: knowledge management, military, bibliometric networks, in-depth text mining, knowledge integration, strategy

\section{Introduction}

Knowledge management in the military has long been an activity related to training and many efforts are related to knowledge sharing among and between the teams and levels of command. In this context, knowledge in the military is perceived as a tool and means for effectiveness and has been analyzed from diverse standpoints. Accordingly, the studies in this field take different paradigms and represent the perspective of management, social networking, organizational psychology, information technology and other fields towards the phenomena of knowledge in the military and its management practices.

The objective of this study is to review current research on knowledge management in military and to identify the main streams where research is performed. Although previous studies on knowledge management in military have presented some literature overviews, this study is the first to provide a systematic analysis using in-depth text mining and networking.

\section{Theoretical Framework for Knowledge Management}

International conflicts, the war on terrorism, the refugee crisis and other global threats on modern countries have accelerated the need for more flexible, rapid strategies and innovative security systems. According to Schulte and Sample (2006), it will continue to constitute a major challenge for democratic governments for many years to come. It is believed that knowledge integration is an important element of the long-term solution to many global threats (Schulte, Sample, 2006; Jyoti, Rani, 2017). In this context, it is growing the importance of knowledge management theory and practice in public sector, including military, organizations.

Ives et al. (1997) analyzing historical aspects of knowledge management, declare that knowledge ,has always been central to human performance and it has been defined as the capacity to act", by the way "knowledge is a high value form of information that is ready to apply to decisions and actions" (p. 269). They also say that the actions of managing knowledge have a long history, starting the earliest pre-writing oral civilizations and finishing the digital age. Therefore, managing knowledge is not a new concept. It is just newly framed and enabled by new technologies, media, devices and techniques (Ives et al., 1997).

Knowledge management in scientific literature (Ives et al., 1997; McCampbell et al., 1999; Schulte, Sample, 2006; Moffett, McAdam, 2009; Jyoti, Rani, 2017; Gao et al., 2018) is named as one of many components of good management in the 21 century. Knowledge management "embodies organizational processes that seek synergistic combination of data 
and information processing capacity of information technologies, and the creative and innovative capacity of human beings" (McCampbell et al., 1999. p. 172). Knowledge management includes the creating, finding, collecting internal knowledge and best practices, then sharing and understanding those practices so they can be used, as well as adapting and applying those practices to new situations (McCampbell et al., 1999; Gao et al., 2018). There are several dimensions of knowledge management in all organizations including organizational structure, organizational performance (financial, employee, operational), learning culture, leadership, content management and technology (Schulte and Sample, 2006; Jyoti, Rani, 2017; Gao et al., 2018).

Analyzing contemporary scientific literature (Gao et al., 2018), reveals such areas of knowledge management as the diversity of the concept of knowledge management, different perspectives of process and stages of knowledge management, knowledge representation, organization and sharing, as well as performance measure for knowledge management.

It is highlighted that effective knowledge transfer often depends on such elements as teams, relations and networks, therefore currently grows up the importance of collaborative knowledge transfer researches (McCampbell et al., 1999; Schulte, Sample, 2006; Jyoti, Rani, 2017). Organizational culture and climate, the factors of information and people (employees) are underlined in the researches, as well (Moffett, McAdam, 2009). There are analyzed such knowledge management dimensions, as knowledge environment, teams, openness, transparency, welfare, support, experimentation, creativity, customer knowledge, risk taking, information capture, information flow and access, external and internal sources, employees' focus on knowledge management, flexibility and ect.). Besides that, it is highlighted the importance of technical climate (Moffett, McAdam, 2009; Jyoti, Rani, 2017). According to Schulte and Sample (2006), technology is not the most important dimension of knowledge management, at the same time most agree that technology enables knowledge sharing, integration and collaboration (Schulte, Sample, 2006).

The significance of knowledge management in military context is also undoubted. Innovation implementation, problem solving and decision-making are more complex and more essential in military situations than ever before. Similarly, practical experience, competence and interaction are also important factors in a military organization's ability to attain knowledge superiority. According to McIntyre et al. (2003), "command and control is taking on new dimensions, and the role of military personnel is evolving into that of 'knowledge worker'" (p. 35). Knowledge management, which facilitates the creation and use of knowledge for increased innovation and value, could have a profound influence on the challenges to be solved by modern military institutions (McIntyre et al., 2003). The review of scientific literature below could help to find out the application of knowledge management principles and techniques in the military context and to determine how knowledge management might be applied to the military environment.

\section{Method}

Systematic literature review is used as a method for this study. The data consist of theoretical, analytical and research papers retrieved from Web of Science Clarivate Analytics (VoS) $(\mathrm{N}=406)$ and Scopus databases (N=317) up to 2018. The only articles covering knowledge management issues in military are selected for the analysis. All together 723 articles were analyzed. The data are analyzed using the VOSviewer software for constructing bibliometric networks using keywords as well as content analysis. These networks are visualized and interpreted using general trends in knowledge management development.

The first step of the analysis is performed creating co-occurrences among keywords from the title and abstract text of the articles. The concepts "knowledge management" and "military" are used to detect a network of interrelated keywords. The keywords were filtered using pre-defined thesaurus words and clustered according to distances among them. Previous example using this method can be found by Holman, Lynch, Reeves (2017). Bibliometric networks are created using cocitation analysis. The network is based on Belli's (2009) assumption that co-citation trace the map of relationships among key concepts, that share some kind of intellectual similarity. In our research these similarities are reflected in bibliometric networks using VOSviewer software.

The second step of the analysis uses in-depth text mining. Term maps are created using a corpus of articles using the same using VOSviewer software. The composition of terms in the maps identifies the distance between two terms and represents the relatedness of the terms. Since we were interested in the trends of knowledge management research in military, the analysis was performed using year of publication as a metric. VoS and Scopus data were analysed separately and two maps were produced out of in-depth text mining.

\section{Results}

Three clusters (conceptual categories) are identified in the analysis. The first and the biggest cluster of research embodies management sciences and is represented by papers in leadership, strategic management as well as another field of military management. The papers analyze how knowledge management is used in planning and executing military operations. This cluster provides new approaches developed by investigating the emerging trends for knowledge exchange in military decision superiority (Bannister, Byrne, 2013), as well as classical military theories are re-examined using knowledge management perspective (see Boe, 2014). The second cluster consists of papers from highly diverse fields where an emphasis is made to integrate different approaches and develop a new attitude in military knowledge management. The researchers take the most challenging issues in military and provide new solutions. As sense making, decision making and learning are identified as a major activities where knowledge creation take place in the military (Mattila, 2016), an integration of these activities are a primal focus of the research. The third cluster represents studies performed in the paradigm of system management. The 
stream reflects a range of technical solutions and best practices in knowledge management system development. Multiagent system to combat terrorism (Galka et al., 2009), fuzzy cognitive maps as a mediator in decision making (Perusich, Mcneese, 2006) and other solutions are presented in the papers of this cluster.

The visualization of all three cluster is presented in Fig. 1. An interrelationship of articles in VoS and their keywords co-occurrences is presented using VOSviewer software. As discussed, three big conceptual categories occur in the analysis. The first (blue) presents management and interrelated topics as leadership and strategy. This category is related to smaller stream that represents organizational learning. The second biggest (red) category is related to knowledge organization, coordination, decision making and other issues related to knowledge management. The third category (green) consist of systems and information maintenance. Identified categories serve as a framework for further analysis using text mining.

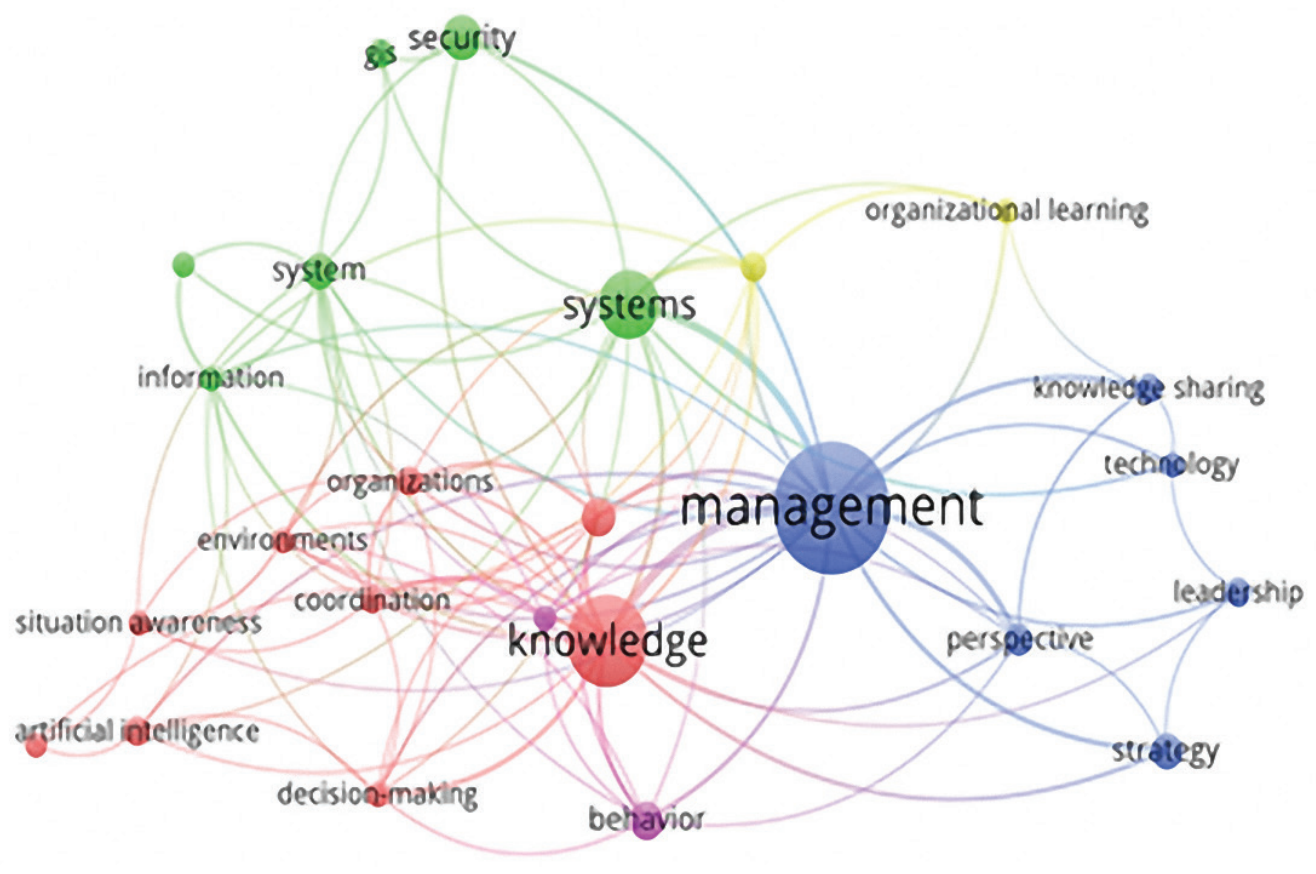

Fig.1. Main streams in knowledge management research in military: inter-relationship of articles

To identify main streams in the research on knowledge management in the military an in-depth text mining was performed. First, we analysed VoS articles. The analysis shows (Fig.2) the main research focus on information and clears research trends over time.
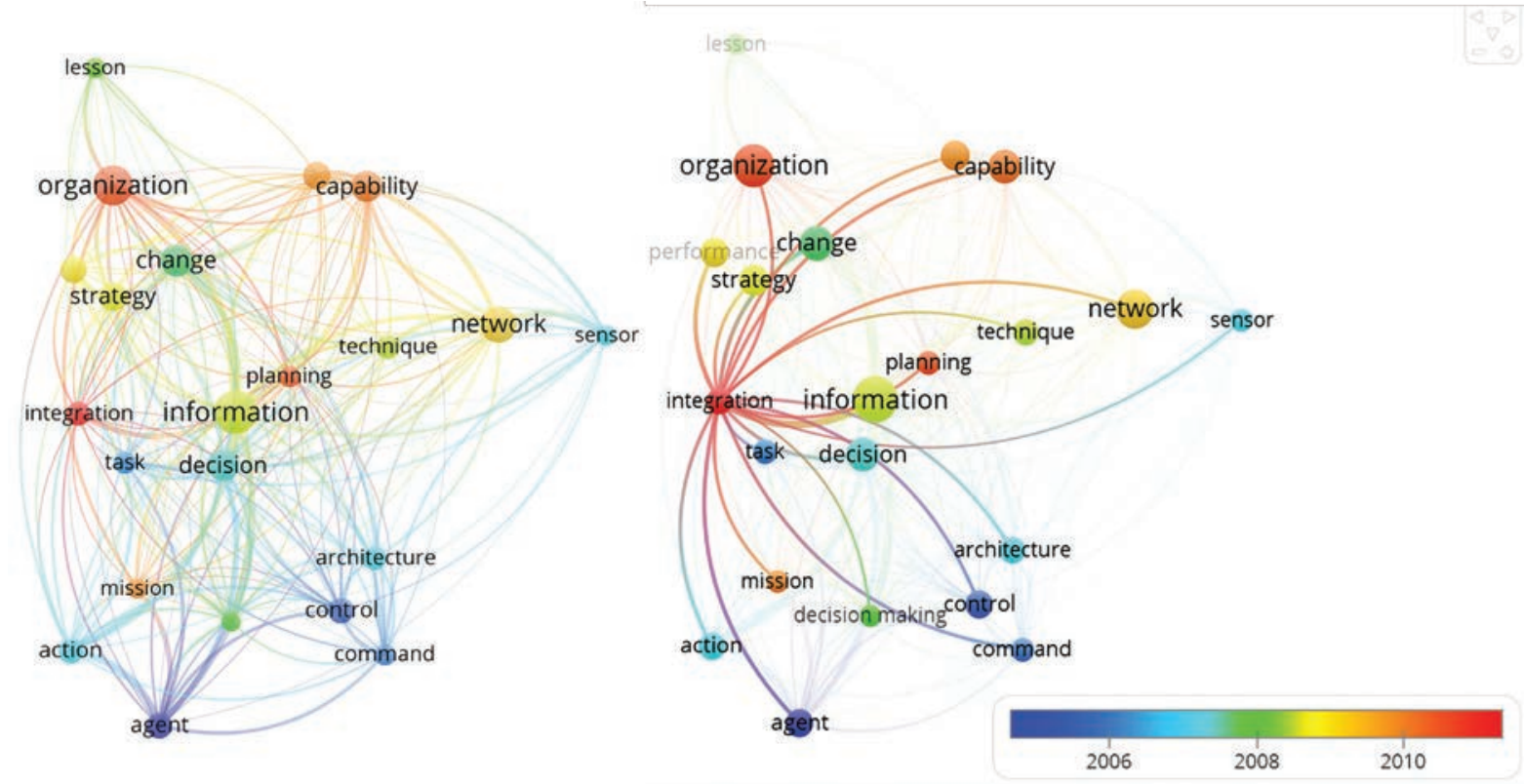

Fig. 2. Clustered results of text mining over time: VoS articles. a) clusters of different time periods; b) topic of integration and its interlinkages 
The articles published before 2006 focus mainly on decision support systems and provide solutions for knowledge management architecture, change agents, present results form web generated sensor data and other technical insights. A short period of 2006-2008 provide research focused on command and control and continues a development of technical solutions as intelligent agents for knowledge management. The period up to 2010 is diverse in sense of research topics. We can find there information and techniques for knowledge identification and maintain as well as focus on knowledge management from the strategic perspective. However, the most recent trends in knowledge management in the military is related to knowledge integration issues. The articles analyse how to manage the unstructured data and integrate it into knowledge lifecycle applicable to military logistics planning (Fitzpatrick et al., 2013), how to integrate the domain knowledge for high-level reasoning (Pai et al., 2017) and collective understanding of the extreme circumstances (Godé, Lebraty, 2015). It is important to add that the topic of knowledge integration follows from previous topics as decision making, information management, change management and others (Fig. 2 b). Therefore the articles analyse not only the standards, methods and tools of knowledge integration (Varga, Bauer, 2017), but also the impact on assurance of efficient and effective solutions in military organizations (Tolk, Aaron, 2010), the significance to the quality of information management and evidence-based practise (Alexander et al., 2017), the interrelations with innovative solutions and other various types of changes in military (Barbulescu at al., 2003).

An analysis of Scopus database presents slightly different results as the dominant topic is related to a system instead of information (Fig.3). The most intensive period of knowledge management in military research starts in 2007 . There similarly to VoS database analysis, the research focus is on technical issues as knowledge architecture, as well as on managerial questions related to command and control or lessons learned. The period of 2009-2010 is marked by a conceptual shift from system and information to strategy and decision making.

The most recent stream in Scopus database is related to strategy (Fig. 3 b) which is interlinked with previous research on command and control, information users and etc.
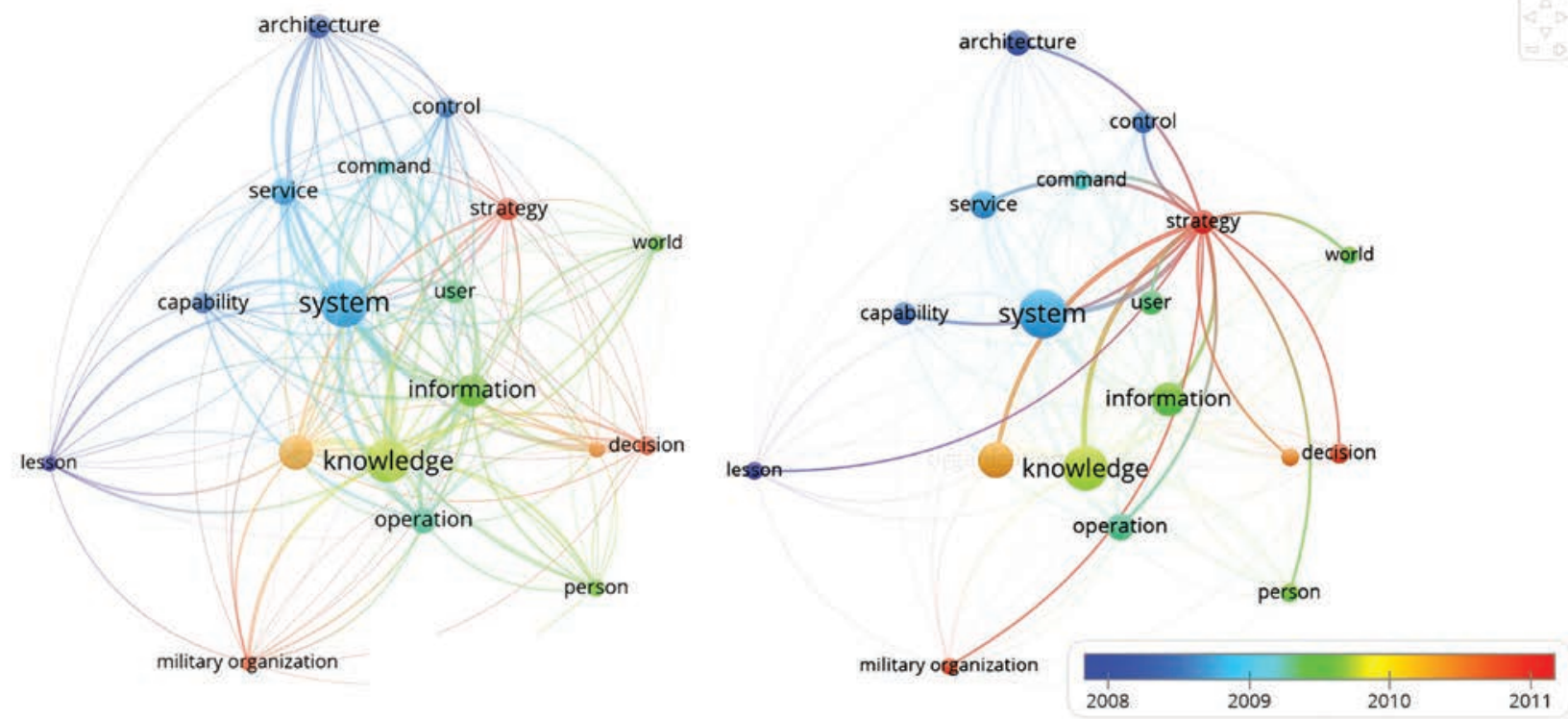

Fig. 3. Clustered results of text mining over time: Scopus articles. a) clusters of different time periods; b) topic of strategy and its interlinkages

The articles present cases of managing strategic science and technology projects in the military (Shore, Zollo, 2014), solutions for strategy development (Mattila, 2016) and decisions for military operations using knowledge management (Strakos et al., 2016). Also, the articles analyze innovative approaches of knowledge management strategies, as ignorance management in multinational organizations (Israilidis et al., 2012) or usage of video-based performance support systems for online management information system (Ruffner et al., 2011). Strategy approach towards knowledge management in military marks a new era in this research field. Knowledge management is perceived as a strategic resource for the organization. It also should be emphasized that strategy is closely interlinked with research of information management. The papers present such information management tools used in the military, as hybrid knowledge visualization (Eppler, Pfister, 2014), grid computer systems (Shrihari et al., 2015), model checking (Bernardi et al., 2015) and etc. There articles illustrates how strategy is converted into techniques and processes and flow from strategic to tactical level.

\section{Conclusions}

We conclude that knowledge management research in the military is performed in three streams where new ideas and solutions are developed. The larges stream identifies management science paradigm and represents classical approach in knowledge management. The second largest stream is created by researchers from diverse disciplines. This stream represents interdisciplinary perspective. The last and the smallest stream is predominated by technical solutions in the 
military knowledge management. To identify main streams in the research on knowledge management in military an indepth text mining was performed.

The analysis of VoS and Scopus databases showed the main research trends over time. The most recent trends in knowledge management research in the military are associated with knowledge integration (in VoS) and strategy (in Scopus). These two trends represent not only the most challenging issues but also outline the prospect breakthrough for the coming years in the field.

\section{References}

1. Alexander K. D., Mazzuchi T. A., Sarkani, S. Knowledge Integration for Predicting Schedule Delays in Software Integration. Engineering Management Journal, 2017, 29(4), p. 223-234. https://doi.org/10.1080/10429247.2017.138 2306

2. Bannister F., Byrne, B. Knowledge Management in Defence. Proceedings of the 14th European Conference on Knowledge Management (Eckm), 2013, 1-2, p. 106-116.

3. Barbulescu M., Balan G., Boicu M., Tecuci, G. Rapid Development of Large Knowledge Bases. Proceedings of the IEEE International Conference on Systems, Man and Cybernetics, 2003, 1-5, p. 2169-2174.

4. Bernardi S., Dranca L., Merseguer, J. Modelling and Verification of Survivability Requirements for Critical Systems. Lecture Notes in Computer Science. 2015, 8938, p. 86-100. https://doi/10.1007/978-3-319-15201-1_6.

5. Boe O. Changing Knowledge Management Strategy in the Norwegian Armed Forces: A Discussion of Effects-Based Thinking as an Alternative Method in the Planning and Execution of Military Joint Operations. 2v. Proceedings of Knowledge Management International Conference, 2014, p. 814-818.

6. De Bellis N. Bibliometrics and Citation Analysis: From the Science Citation Index to Cybermetrics. 2009, Lanham, Md., Plymouth: Scarecrow Press.

7. Eppler M. J., Pfister, R. Best of Both Worlds: Hybrid Knowledge Visualization in Police Crime Fighting and Military Operations. Journal of Knowledge Management, 2013, 18(4), p. 824-840. https://doi/10.1145/2494188.2494214.

8. Fitzpatrick D., Ratte S., Coallier, F. RA-EKI: A Use Case for Collaborative Logistics Planning in Coalition Force Deployment. Military Communications and Information Systems Conference (MCC), 2013, p. 1-5.

9. Galka A., Jarema P., Krasowski K., Kosinski A., Chmielewski M., Nguyen N. T., Kowalczyk, R. Semantic Knowledge Representation in Terrorist Threat Analysis for Crisis Management Systems. Lecture Notes in Computer Science, 2009, 5796, p. 460-471.

10. Godé C., Lebraty J. F. Experience Feedback as an Enabler of Coordination: an Aerobatic Military Team Case. Scandinavian Journal of Management, 2015, 31(3), p. 424-436. https://doi.org/10.1016/j.scaman.2015.02.002.

11. Holman D., Lynch R., Reeves A. How Do Health Behaviour Interventions Take Account of Social Context? A Literature Trend and Co-citation Analysis. Health, 2017, 22 (4), p. 389 - 410. https://doi.org/10.1177/1363459317695630.

12. Israilidis J., Lock R., Cooke, L. Ignorance Management: An Alternative Perspective on Knowledge Management in Multinational Organisations. Proceedings of the European Conference on Knowledge Management, 2012, 1, p. 493501.

13. Ives W., Torrey B., Gordon C. Knowledge Management: An Emerging Discipline with a Long History. Journal of Knowledge Management, 1997, 1 (4), p. 269-274. https://doi.org/10.1108/EUM0000000004598.

14. Mattila J. Military Knowledge Management: Sense-Making, Decision Making and Knowledge Creation. Proceedings of the 17th European Conference on Knowledge Management, 2016, p. 1053-1062.

15. McCampbell A. S., Clare L. M., Gitters S. H. Knowledge Management: the New Challenge for the 21st Century. Journal of Knowledge Management, 1999, 3 (3), p. 172-179. DOI: 10.1108/13673279910288572.

16. McIntyre S.G., Gauvin M., Waruszynski B. Knowledge Management in the Military Context. Canadian Military Journal, 2003, 4(1), p. 35-40.

17. Moffett S., McAdam R. Knowledge Management: a Factor Analysis of Sector Effects. Journal of Knowledge Management, 2009, 13 (3), p. 44-59. https://doi.org/10.1108/13673270910962860.

18. Pai F. P., Yang L. J., Chung, Y. C. Multi-layer Ontology Based Information Fusion for Situation Awareness. Applied Intelligence, 2017, 46(2), p. 285-307. https://doi.org/10.1007/s1048.

19. Perusich K., Mcneese M. D. Using Fuzzy Cognitive Maps for Knowledge Management in a Conflict Environment. IEEE Transactions on Systems, Man and Cybernetics, Part C (Applications and Reviews), 2006, 36(6), 810-821. https://doi.org/10.1109/TSMCC.2005.855509.

20. Philp W. R., Martin Ch. P. A Philosophical Approach to Time in Military Knowledge Management. Journal of Knowledge Management, 2009, 13 (1), p. 171-183. https://doi.org/10.1108/13673270910931242.

21. Ruffner J. W., Sammons A. D., Tewkesbury W. R. Video-based Performance Support Development for an Online Management Information System. Proceedings of the Human Factors and Ergonomics Society, 2011, p. 500-504. https://doi/10.1177/1071181311551103.

22. Schulte W. D., Sample T. Efficiencies From Knowledge Management Technologies in a Military Enterprise. Journal of Knowledge Management, 2006, 10 (6), p. 39-49. https://doi.org/10.1108/13673270610709206.

23. Shore B., Zollo G. Managing Large-Scale Science and Technology Projects at the Edge of Knowledge: the Manhattan 
Project as a Learning Organisation. International Journal of Technology Management, 2014, 67(1), p. 26-46. https:// doi.org/10.1504/IJTM.2015.065895.

24. Shrihari S.V., Pawan K., Vishnu M., Mahajan S. Technological Aspects of Grid Computing. 2nd International Conference on Electronics and Communication Systems (ICECS), 2015, p. 1463-1468. https://doi/0.1109/ ECS.2015.7124829

25. Strakos J.K., Quintanilla J. A., Huscroft J. R. Department of Defense Energy Policy and Research: A Framework to Support Strategy. Energy Policy, 2016, 92, p. 83-91. https://doi/10.1016/j.enpol.2016.01.036

26. Tolk A., Aaron R. D. Addressing Challenges of Transferring Explicit Knowledge, Information, and Data in Large Heterogeneous Organizations: a Case Example from a Data-Rich Integration Project at the US Army Test and Evaluation Command. EMJ - Engineering Management Journal, 2010, 22 (2), p. 44-55. https://doi.org/10.1080/1042 9247.2010.11431863.

27. Varga N. L., Bauer P. J. Using Event-related Potentials to Inform the Neurocognitive Processes Underlying Knowledge Extension through Memory Integration. Journal of Cognitive Neuroscience, 2017, 29 (11), p. 1932-1949. https://doi. org/10.1162/jocn_a_01168.

28. Jyoti J., Rani A. High Performance Work System and Organisational Performance: Role of Knowledge Management. Personnel Review, 2017, 46 (8), p. 1770-1795. https://doi.org/10.1108/PR-10-2015-0262.

29. Gao T., Chai Y, Liu Y. A Review of Knowledge Management About Theoretical Conception and Designing Approaches, International Journal of Crowd Science, 2018. https://doi.org/10.1108/IJCS-08-2017-0023. 